\title{
Assessment of expected damage on buildings subjected to Lorca earthquake through an energy-based seismic index method and nonlinear dynamic response analyses
}

\author{
A. Benavent-Climent A. Escobedo J. Donaire-Avila \\ E. Oliver-Saiz A. L. Ramírez-Márquez
}

\begin{abstract}
The city of Lorca (Spain) was hit on May 11th, 2011, by two consecutive earthquakes of magnitudes 4.6 and $5.2 \mathrm{M}_{\mathrm{W}}$, causing casualties and important damage in buildings. Many of the damaged structures were reinforced concrete frames with wide beams. This study quantifies the expected level of damage on this structural type in the case of the Lorca earthquake by means of a seismic index $I_{v}$ that compares the energy input by the earthquake with the energy absorption/dissipation capacity of the structure. The prototype frames investigated represent structures designed in two time periods (1994-2002 and 2003-2008), in which the applicable codes were different. The influence of the masonry infill walls and the proneness of the frames to concentrate damage in a given story were further investigated through nonlinear dynamic response analyses. It is found that (1) the seismic index method predicts levels of damage that range from moderate/severe to complete collapse; this prediction is consistent with the observed damage; (2) the presence of masonry infill walls makes the structure very prone to damage concentration and reduces the overall seismic capacity of the building; and (3) a proper hierarchy of strength between beams and columns that guarantees the formation of a strong column-weak beam mechanism (as prescribed by seismic codes), as well as the adoption of counter-measures to avoid the negative interaction between non-structural infill walls and the main frame, would have reduced the level of damage from $I_{v}=1$ (collapse) to about $I_{v}=0.5$ (moderate/severe damage).
\end{abstract}




\section{Introduction}

Lorca is a small city located in southeast Spain, settled over a segment of the Murcia-TotanaLorca fault. On May 11th, 2011, it was hit by two consecutive earthquakes with respective magnitudes of 4.6 and $5.2 \mathrm{M}_{\mathrm{w}}$. Although the magnitudes of these ground motions were not severe, considerable damage was done to a great number of buildings. Since then, more than 300 have been demolished and many others are being retrofitted. According to data provided by the Lorca town council, 144 buildings built in the period 1994-2002 suffered damage of grade 3 (heavy damage), 4 (very heavy damage) or 5 (destroyed), measured with the EMS-98 scale (Scales 1998). The number of buildings with damage grade within this range that were built in the period 2003-2008 was 70. On the whole, the number of damaged buildings corresponding to these two time periods represents an important percentage of the total amount of modern reinforced concrete (RC) constructions severely damaged by the Lorca earthquake. Many buildings that suffered severe damage consisted of RC frames with wide beams, a very common structural typology in the Mediterranean area. In the vibration period range corresponding to low- to mid-rise buildings, the elastic response spectrum of the Lorca earthquake greatly exceeded that prescribed by the Spanish seismic code. Also, according to code prescriptions, these structures should have been designed with an elastic response reduction factor $\mu$ of at most $\mu=2$, where $\mu$ is defined by:

$$
\mu=\delta_{u} / \delta_{y},
$$

here, $\delta_{u}$ is the ultimate displacement and $\delta_{y}$ the yield displacement.

Adopting a $\mu>1$ implies that structural damage (i.e. plastic strain deformations) is expected, but it does not suffice to explain in quantitative terms the actual level of damage to many buildings. The elastic design spectrum is not a reliable measure of the destructiveness of a design earthquake. Moreover, interpreting $\mu$ as a function of a presumed energy dissipation capacity of a structure is highly questionable. In fact, these are two controversial and uncertain aspects of the strength-based seismic design approach currently adopted by most codes (Decanini and Mollaioli 1998). The elastic design spectrum modified by the reduction factor does not contain all the information necessary to characterize damage potential (i.e. durationrelated cumulative damage). It has long been recognized that the energy-based approach is preferable for appraising the demands placed on structures during earthquakes and the earthquake resistance of the building. The introduction of appropriate parameters formulated in terms of energy might lead to more reliable predictions, and a more rational estimation of the mechanisms of generation, transmission and destructiveness of seismic actions (Decanini and Mollaioli 1998).

The susceptibility of a structure to damage can be assessed using empirical or analytical methods (Calvi et al. 2006). Empirical methods are based on the damage observed after earthquakes, while analytical methods replace these data with the results of extensive nonlinear dynamic response analyses. Within the second group, several simplified inelastic procedures for seismic assessment have been proposed (Fajfar and Gaspersic 1996; Applied Technology Council 1996; Calvi 1999; Cosenza et al. 2005; Borzi et al. 2008). These procedures combine the nonlinear static (pushover) analysis of a relatively simple mathematical model with the response spectrum approach. More recently, Benavent-Climent $(2011 \mathrm{a}, \mathrm{b})$ proposed an analytical method that evaluates seismic vulnerability in terms of an energy-based seismic index $I_{v}$. Accordingly, the seismic demand of the ground motion is characterized in terms of input energy by means of a normalized input energy spectrum and a normalizing factor called the Seismic Hazard Energy Factor $A E_{I}$ (Decanini et al. 1995; Sucuoglu and Nurtug 1995). The earthquake resistance of the structure is characterized in terms of two counter- 
part energy factors, $A E_{I S}$ and $A E_{I U}$. Factor $A E_{I S}$ represents the level of the "maximum earthquake", with the aforementioned normalized input energy spectrum, that the frame can sustain within the elastic range. Factor $A E_{I U}$ characterizes the level of the "ultimate earthquake", with the aforementioned normalized input energy spectrum, that would cause the collapse of the structure. The seismic index $I_{v}$ method takes directly into account the effects of cumulative damage and damage concentration on a given story, which are especially important in existing buildings designed according to earlier codes. The seismic index $I_{v}$ method takes explicitly into account the relation between the dynamic properties of the frame and the energy input spectral shape of the ground motion. This makes the method particularly adequate for quantifying the expected level of damage in structures subjected to a given ground motion characterized by its energy input spectrum.

This paper evaluates the level of damage expected in typical RC frames with wide beams subjected to the recent Lorca earthquake by means of an energy-based seismic index $I_{v}$ method (Benavent-Climent 2011a). The study focuses on residential constructions built in the last two decades that are assumed to be designed according to seismic codes. Two chronological windows were established. The first is from the year 1994 to 2002, when the RC and seismic codes in force in Spain were EH-91 (Ministerio de Obras Públicas y Transportes 1991) and NCSE-94 (Ministerio de Obras Publicas 1995), respectively. The second window is from 2003 to 2008 , when the respective $\mathrm{RC}$ and seismic codes in force were EH-98 (Fomento 1998) and NCSE-02 (Fomento 2003). The energy-based seismic index method compares the energy input by the Lorca earthquake with the energy absorption/dissipation capacity of the structure. This comparison yields an energy-based seismic index $I_{v}$ that evaluates the level of damage on a scale ranging from 0 (no damage) to 1 (collapse). The study is completed with nonlinear dynamic response analyses of numerical models calibrated with experimental results. These analyses clarify the role played by the non-structural infill walls, pointing out their influence on damage distribution among the stories.

\section{Murcia-Totana-Lorca fault and earthquakes of May 2011}

Lorca is a city of 92,000 inhabitants situated in a very active seismic zone in southeastern Spain, where the European and African tectonic plates converge. It is included in the Mediterranean basin, an area of moderate seismicity. The earthquakes that took place on May 11th, 2011, had hypocenters less than $5 \mathrm{~km}$ deep, by the NW edge of town, and the distance from the epicentre to the centre of Lorca was $5.5 \mathrm{~km}$; they caused a great amount of damage to buildings, as well as deaths and injuries. Although the respective shocks reached intensities VI and VII (EMS) in Lorca, soil movement parameters such as Arias and Spectral intensity suggest a maximum intensity of VIII. Directivity effects and soft soil influence also show different levels of intensity according to the distribution of damage throughout the city. The second earthquake (main shock), was the strongest ever registered with accelerometers in Spain, reaching a peak ground acceleration $(P G A)$ of $0.36 \mathrm{~g}$ ( $\mathrm{g}$ being the acceleration of gravity). The design PGA established by the current Spanish seismic code, NCSE-02 (Fomento 2003) for Lorca is $0.12 \mathrm{~g}$. The earthquakes are attributed to the Murcia-Totana-Lorca fault (IGME 2011; Vissers \& Meijninger 2011), a major $80 \mathrm{~km}$ long fault that runs close to the city centre. From a seismological point of view, the 2011 earthquake was not an outstanding event in its regional context. In Murcia, three recent earthquakes with $M_{w}=4.8, M_{w}=5.0$ and $M_{w}=4.8$ occurred in 1999, 2002 and 2005, respectively (Mancilla et al. 2002). It is worth emphasizing, however, that the meaningful duration of the main shock (i.e. elapsed time between 5 and $95 \%$ of Arias Intensity) was $0.935 \mathrm{~s}$. This is an extremely small value, 
indicating that the earthquake supplied energy to the structures in a very short period of time, which is a typical feature of the near fault source.

\section{Input energy of Lorca earthquake}

The equation of motion of an inelastic single degree of freedom (SDOF) system subjected to a unidirectional horizontal ground motion is:

$$
m \ddot{y}_{t}+c \dot{y}+Q(y)=0
$$

where $m$ is the mass; $y_{t}$ is the total or absolute displacement of the mass, that is, the sum of the relative displacement of the mass with respect to the ground, $y$, and the ground displacement, $z_{g}$, i.e. $y_{t}=y+z_{g} ; c$ is the damping coefficient and $Q(y)$ the restoring force. The dots in the variables indicate the derivates with respect to time $t$. Integrating Eq. (2) with respect to relative displacement $y$ gives:

$$
\int m \ddot{y}_{t} d y+\int c \dot{y} d y+\int Q(y) d y=0
$$

Replacing $y$ by $\left(y_{t}-z_{g}\right)$ in the first term of Eq. (3) and noting that $d y_{t}=\dot{y}_{t} d t$ gives:

$$
\int m \ddot{y}_{t} d y=\int m \ddot{y}_{t}\left(d y_{t}-d z_{g}\right)=\int m \frac{d \dot{y}_{t}}{d t} d y_{t}-\int m \ddot{y}_{t} d z_{g}=\frac{m\left(\dot{y}_{t}\right)^{2}}{2}-\int m \ddot{y}_{t} d z_{g}
$$

Substituting Eq. (4) in Eq. (3) and noting that $d y=\dot{y} d t$ and $d z_{g}=\dot{z}_{g} d t$, gives:

$$
E_{k}+E_{\xi}+E_{a}=E
$$

where:

$$
E_{k}=\frac{m\left(\dot{y}_{t}\right)^{2}}{2} ; \quad E_{\xi}=\int c \dot{y}^{2} d t ; \quad E_{a}=\int Q(y) \dot{y} d t ; \quad E=\int m \ddot{y}_{t} \dot{z}_{g} d t
$$

In the left-hand-side term, $E_{k}$ is the absolute kinetic energy, $E_{\xi}$ is the damping energy and $E_{a}$ is the absorbed energy. The right-hand-side term $E$ is, by definition, the so-called "absolute" energy input to be distinguished from the "relative" energy input also used in energy-based seismic design. In the period range of practical interest, the absolute and the relative input energies are very close (Uang and Bertero 1990). $E_{a}$ is composed by the recoverable elastic strain energy, $E_{s}$, and the irrecoverable hysteretic energy $E_{h}$, i.e. $E_{a}=E_{s}+E_{h}$, so that Eq. (5) is rewritten

$$
E_{k}+E_{\xi}+E_{S}+E_{h}=E .
$$

Equation (6) holds as well for multi-degree of freedom (MDOF) systems-i.e. a $N$-story building-if the scalars are replaced by the corresponding matrices and vectors. Housner (1956) defined $E_{D}=E-E_{\xi}$ as the energy that contributes to damage. $E$ and $E_{D}$ can be expressed in terms of equivalent velocities $V_{E}, V_{D}$, defined as follows:

$$
V_{E}=\sqrt{\frac{2 E}{M}} ; \quad V_{D}=\sqrt{\frac{2 E_{D}}{M}}
$$

where $M$ is the total mass of the system. By calculating $V_{E}$ for SDOF systems with different periods $T$, the corresponding energy input spectrum, $V_{E}-T$, is determined. The $V_{E}-T$ spectrum of the horizontal ground motion varies depending on the direction considered. The history of acceleration in a given horizontal direction defined by the angle $\theta$ that it forms 
with the $\mathrm{N}$ direction is simply determined by projecting the NS and EW components of acceleration in the $\theta$ direction. Once the acceleration history in the $\theta$ direction is known, the corresponding $V_{E}-T$ spectra can be calculated. The most demanding scenario in terms of energy input in buildings is the one that presents the highest spectral values of $V_{E}$, and it can take place in any direction $\theta$. To determine the direction $\theta$ corresponding to the highest spectral values of $V_{E}$, the $5 \%$ damped energy input spectrum was calculated for a set of directions $\theta$. This set contained one hundred values of $\theta$, from $\theta=-45^{\circ}$ to $\theta=+45^{\circ}$, increasing with increments of $1.8^{\circ}$. The damping ratio of $5 \%$ was adopted because it is the amount of inherent damping commonly recommended by many codes (i.e. NCSE-02) for RC structures of residential buildings. Further, $5 \%$ is the common reference damping adopted by many seismic codes (NCSE-94, NCSE-02, Eurocode 8, etc.) to define the elastic response spectra. The $V_{E}-T$ spectra obtained in this way for the second (main) shock in Lorca are shown with thin lines in Fig. 1a. As can be seen, the highest spectral values take place in the direction $\theta=23^{\circ}$ (indicated as $\mathrm{N} 23 \mathrm{~W}$ ). Furthermore, the $V_{E}-T$ spectrum for $\mathrm{N} 23 \mathrm{~W}$ is very close to the approximate spectrum $V_{E \text {, approx }}-T$ obtained by using Akiyama's approach (Akiyama 1985) as follows:

$$
V_{E, \text { approx }}=\sqrt{V_{E, N S}^{2}+V_{E, E W}^{2}}
$$

where $V_{E, N S}$ and $V_{E, E W}$ are the energy input spectra of the NS and EW components of the ground motion. Figure 1a also shows, with thick solid lines, the design energy input spectrum proposed by Benavent-Climent et al. (2002) for moderate seismicity regions and soft-medium soil conditions, assuming the PGA $=0.12 \mathrm{~g}$ prescribed by code NCSE-02 for Lorca. It can be seen that the proposed design $V_{E}-T$ spectrum is very close to the $V_{E}-T$ spectrum of the most demanding direction $(\mathrm{N} 23 \mathrm{~W})$ in the period range of $0 \leq T \leq 0.35 \mathrm{~s}$, which is approximately the period range of buildings of up to four stories. In this range, the Lorca earthquake exceeded up to 1.5 times the $V_{E}$ proposed by Benavent-Climent et al. (2002), that is plot in Fig. 1b. Likewise seen in Fig. Ib are the input energy spectra implicit in the Spanish seismic code NCSE-02, for soft and for medium soil conditions. They were estimated from the absolute acceleration response spectra $S_{a}-T$ prescribed by the Spanish seismic code on the basis of the following considerations: (1) the spectral absolute acceleration $S_{a}$ of a damped elastic SDOF system is related to the pseudo-velocity spectral response, $S_{p v}$, by $S_{a}=\omega S_{p v}$, where $\omega$ is the circular frequency; (2) except in the range of the shorter natural periods, $S_{p v}$, provides a good approximation of $V_{D}$ (Housner 1956); and (3) $V_{E}$ can be estimated from $V_{D}$ by the following approximate equation (Akiyama 1985):

$$
\frac{V_{D}}{V_{E}}=\frac{1}{1+3 \xi+1.2 \sqrt{\xi}}
$$

where $\xi$ is the fraction of damping. It is shown in Fig. 1a that the input energy spectra implicit in the Spanish seismic code is clearly below the levels of energy input by the Lorca earthquake in the range $0 \leq T \leq 0.75 \mathrm{~s}$. Figure $1 \mathrm{c}$ shows in detail the $V_{E}-T$ spectrum in the $\mathrm{N} 23 \mathrm{~W}$ direction of the first and second shocks of the Lorca earthquake; whereas the shapes are very similar, the intensity is drastically different.

\section{Damages observed in buildings after Lorca earthquake}

The damage in the city of Lorca after the earthquake was widespread. To some degree of severity, the ground motion affected over $80 \%$ of the building stock of the city. Various levels 
(a)

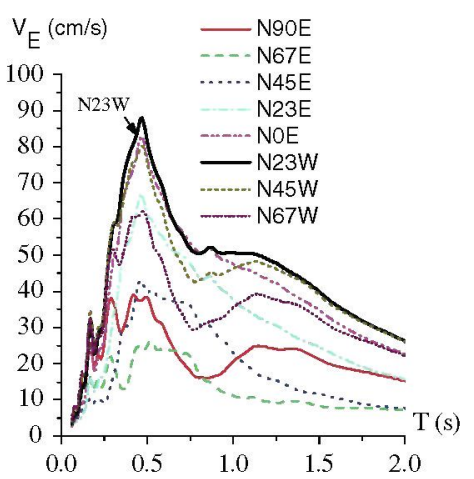

(b)

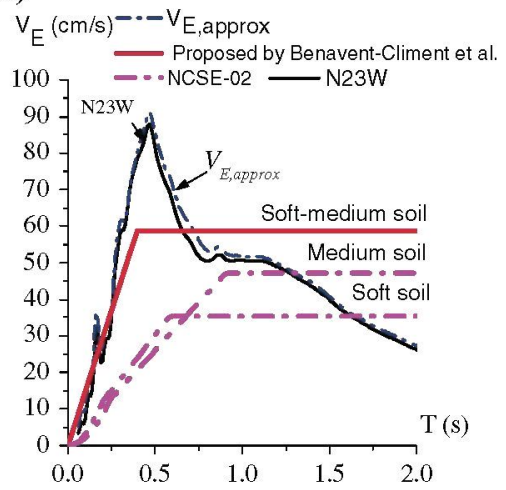

(c)

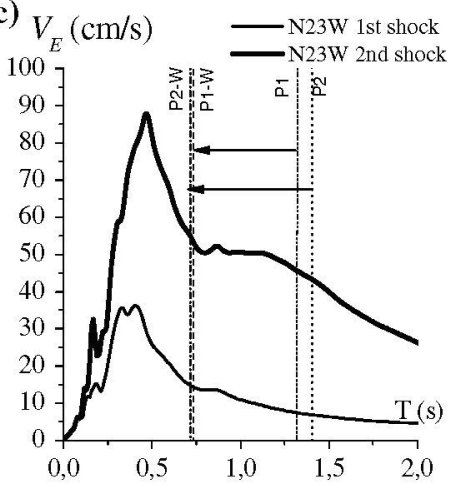

Fig. 1 Input energy spectra of Lorca earthquake; a Second (main) shock; b first and second shock; $\mathbf{c}$ N23W direction of first and second shocks

of damage, measured with the EMS-98 scale, were observed: 4,035 constructions suffered damage level 2; 1,328 buildings experienced damage level 3; 689 buildings showed damage level 4 and in 329 buildings the level of damage was 5 . The severest damage (levels 4 and 5 ) was found mostly in four-story buildings. A large number of buildings with three to five stories and wide openings in the ground floor exhibited a "soft-story" mechanism that drove the buildings to the brim of complete collapse, as shown in Fig. 2. A more detailed description of the damage can be found in (Benavent-Climent et al. 2012).

Most of the damaged buildings used RC frames with wide beams supporting one-way joists as the structural system. While this system has been widely employed to withstand gravity loads in Spain, it is not recommended in many international codes, such as ACI (ACI Committee 318-08 2008), for withstand seismic loads due to its limited energy dissipation capacity, large flexibility, etc. In Spain, the former seismic code PDS-74 (Ministerio de Obras Publicas 1974) did not include any provision or limitation on the use of RC frames with wide beams. Later, the code NCSE-94 (Ministerio de Obras Publicas 1995) banned its use in seismic areas with design PGA, $a_{c}$, larger than $0.16 \mathrm{~g}$, and penalized the strength reduction factor $\mu$ to a value of 2 in regions with $a_{c}<0.16 \mathrm{~g}$. The current code NCSE- 02 (Fomento 2003 ) allows the use of $\mathrm{RC}$ frames with wide beams in regions with $a_{c} \geq 0.16 \mathrm{~g}$, but limiting the elastic response reduction factor to $\mu=2$, and prescribing special requirements on the width of the beam and on the distribution of the longitudinal bars. The main reason behind the extensive use of RC frames with wide beams is basically one of an economic nature. 

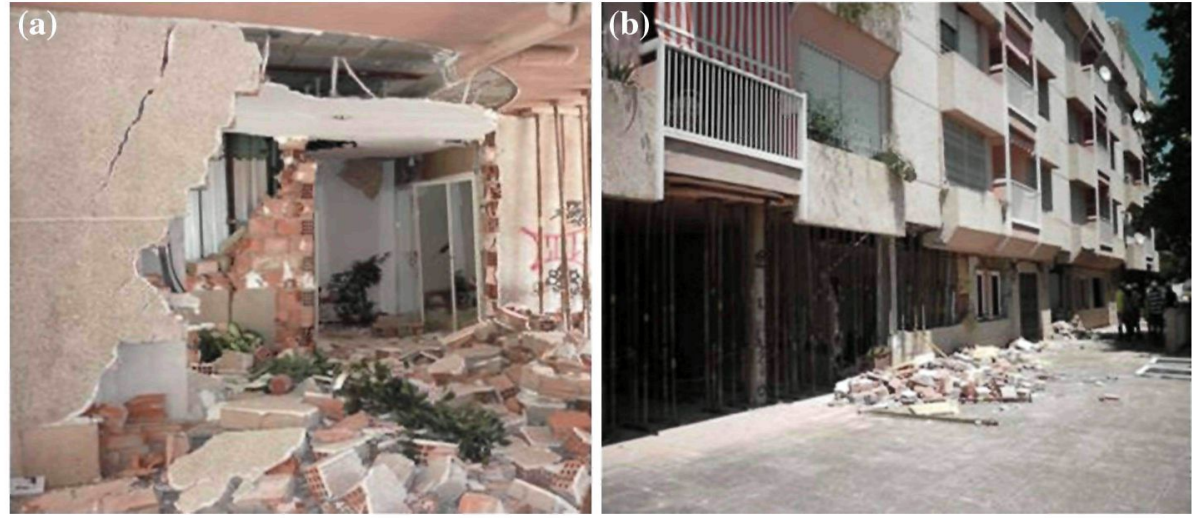

Fig. 2 Damage concentration on ground floor of a 4-story building after Lorca earthquake 2011

(a)

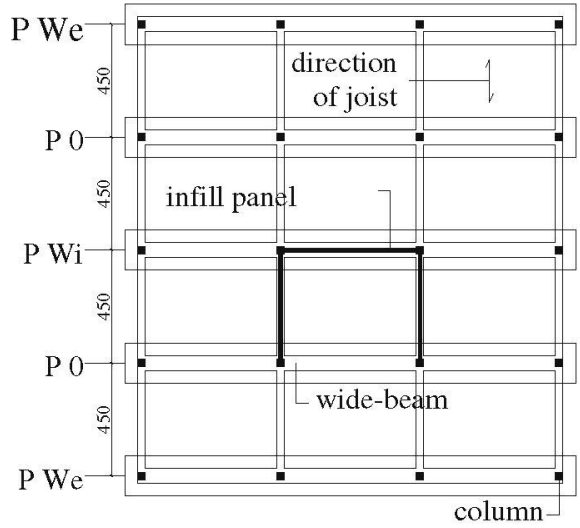

(b)

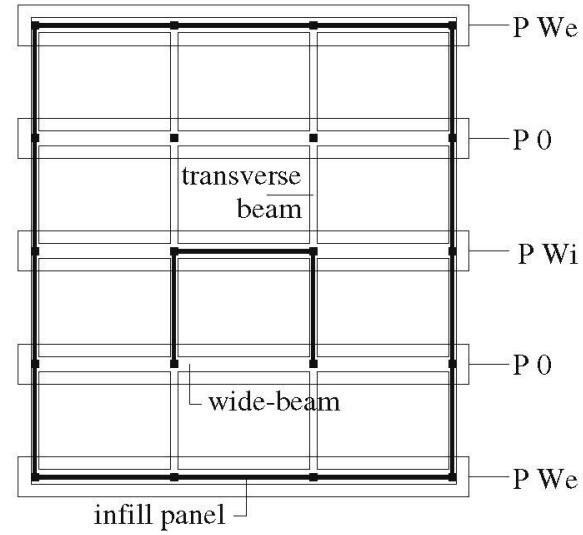

Fig. 3 Plan of the prototypes: a Ground floor; $\mathbf{b}$ rest of the stories

\section{Prototype buildings and numerical models}

\subsection{Design of the prototypes}

Two prototype buildings with the same number of stories (four), spans (three) and bays (four) were designed as shown in Fig. 3. They will be referred to as P1-W and P2-W hereafter. The number of stories adopted was four, because the largest number of buildings that experienced damage of level 4 or 5 had this height. The prototype buildings included the masonry infill walls that are typically present in residential buildings. Figures 4 and 5 show the elevation of three of the five typical frames. Indicated in the figures is the size (width $\times$ depth) of the members in centimetres. The remaining two frames are identical to those shown in Figs. 4a, $\mathrm{b}$ and $5 \mathrm{a}, \mathrm{b}$. Prototypes P1-W and P2-W include masonry infill walls that are indicated by shaded areas in Figs. 4 and 5. Prototype P1-W represents a typical building designed in Spain in the period 1994-2002, following the prescriptions of RC code EH-91 (Ministerio de Obras Públicas y Transportes 1991) and seismic code NCSE-94 (Ministerio de Obras Públicas y Transporte 1995). The prototype P2-W represents a typical building designed in Spain in 
(a)

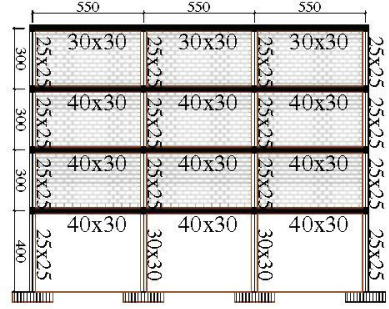

(b)

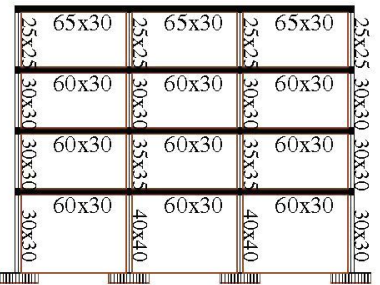

(c)

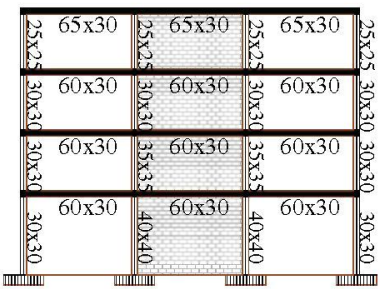

Fig. 4 Frame elevation of prototype P1-W: a Exterior PWe, b interior P0; $\mathbf{c}$ central frame PWi

(a)

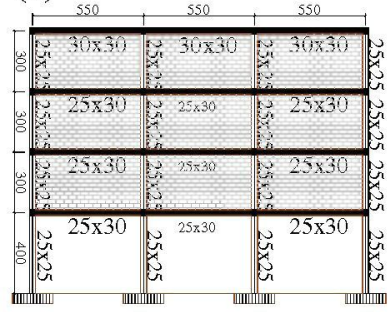

(b)

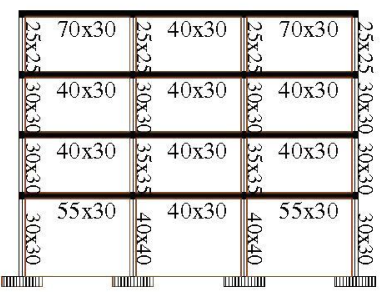

(c)

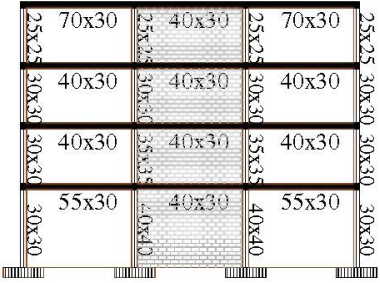

Fig. 5 Frame elevation of prototype P2-W: a Exterior PWe; $\mathbf{b}$ interior P0; $\mathbf{c}$ central frame PWi

the period 2003-2008, following the prescriptions of RC code EH-98 (Fomento 1998) and seismic code NCSE-02 (Fomento 2003). The structures were calculated with the software Tricalc (Artec S.A. 2010). Following the common practice in Spain, the infill walls were not considered as structural elements in the calculations.

The RC code EH-91 required a minimum strength for concrete $f_{c}$ of $17.5 \mathrm{MPa}$, while code EH-98 increased it to $f_{\mathrm{c}}=25 \mathrm{MPa}$. The value $17.5 \mathrm{MPa}$ is too low, and the common practice in Spain nowadays is to employ concrete with at least $f_{\mathrm{c}}=25 \mathrm{MPa}$. Before 1998 , however, it was common to use $f_{\mathrm{c}}=17.5 \mathrm{MPa}$ most likely due to the cost. As for the reinforcement, steels with yield stress of both 400 and $500 \mathrm{MPa}$ were used in the two periods investigated. The latter yield stress became more common in the period 2002-2008. To more clearly identify the cause of possible differences in the seismic response of the two prototypes, the authors decided to limit the number of different design parameters. Accordingly, the two prototypes were designed with different concrete strengths but with the same steel yield stress. In prototype $\mathrm{P} 1-\mathrm{W}, f_{\mathrm{c}}$ was $17.5 \mathrm{MPa}$, while in prototype $\mathrm{P} 2-\mathrm{W}$ a concrete strength of $25 \mathrm{MPa}$ was used. This difference led to different sizes in beams and columns, as seen by comparing Figs. 4 and 5. For both prototypes, the yield strength of the steel was $400 \mathrm{MPa}$. The same gravity loads were considered in both prototypes: (a) self-weight plus dead loads on intermediate floors: $4.25 \mathrm{kN} / \mathrm{m}^{2}$; (b) self-weight plus dead load of the roof: $3 \mathrm{kN} / \mathrm{m}^{2}$; and (c) live loads $3.2 \mathrm{kN} / \mathrm{m}^{2}$. Column size ranged from $25 \times 25 \mathrm{~cm}$ up to $40 \times 40 \mathrm{~cm}$. Beam size ranged from $b \times h=40 \times 30 \mathrm{~cm}$ to $70 \times 30 \mathrm{~cm}$, where $b$ is the width of the wide beam and $h$ is the depth. As for the seismic loads, a modal spectral analysis was carried out and an elastic response reduction factor of $\mu=2$ was adopted in both prototypes. The design PGA was 0.11 and $0.12 \mathrm{~g}$ for prototypes $\mathrm{P} 1-\mathrm{W}$ and $\mathrm{P} 2-\mathrm{W}$, respectively. Similar soil conditions (type II, medium-stiff to stiff soil) were used for designing the prototypes. The selection of these conditions was based on a previous study (Navarro et al. 2008) that classified the soil of Lorca in types I (A and B), II and III, ranging from stiff to soft. Among them, type II was 


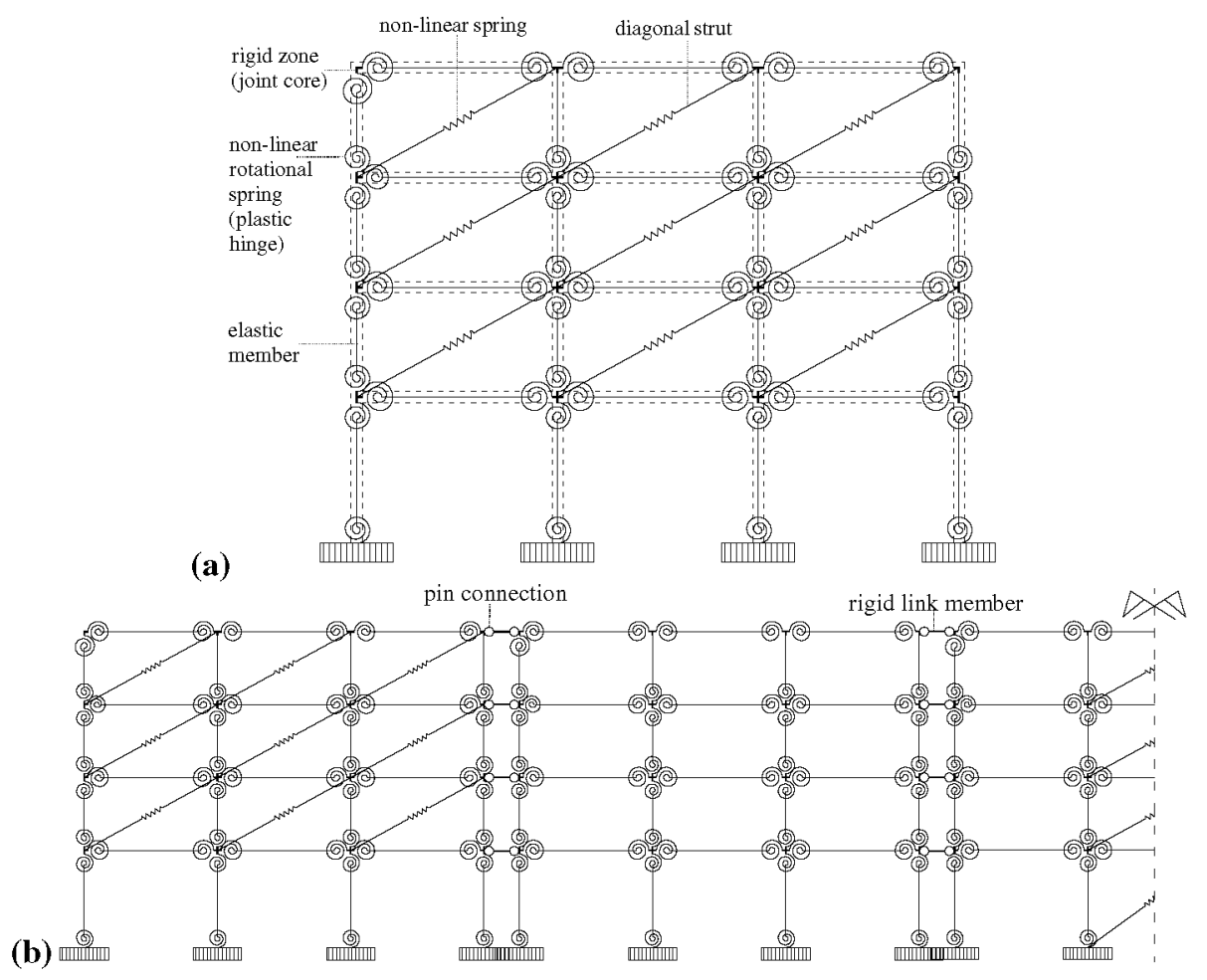

Fig. 6 Numerical model: a Typical frame; b whole structure

selected as an intermediate type of soil in which a large number of damaged buildings were founded. It is worth noting that in both, the dimensions and amounts of reinforcing steel on the RC members were determined with the only condition that the nominal strength of the members be larger than the required values demanded by an elastic analysis under the gravitational and lateral seismic loads combined as determined by the codes. That is, it was not guaranteed in the design of the prototypes that the sum of nominal flexural strengths of columns would be larger than the sum of nominal flexural strengths of the beams framing into the joints, in order to force development of a strong column-weak beam type of collapse mechanism. This was the common practice in Spain in the periods of time investigated. The philosophy of capacity design is now being introduced in Spain, but it was not common at all during the periods investigated.

\subsection{Numerical models}

A nonlinear numerical model was developed for each prototype using the IDARC 6.1 code (Park et al. 1987). Figure 6a shows the numerical model of a typical RC frame with infill walls. Five frames were connected in parallel to represent the whole structure in the direction of seismic loading, as shown in Fig. 6b. Due to symmetry, only one half of the whole numerical model is shown in Fig. 6b. Beams and columns were idealized as frame members with lumped plastic hinges at both ends. Plastic hinges were modelled with nonlinear rotational spring elements. The cyclic behaviour of the plastic hinges was idealized using the polygonal 


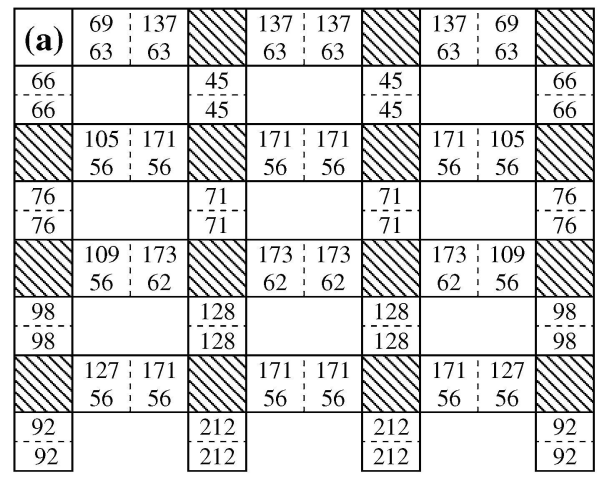

\begin{tabular}{|c|c|c|c|c|c|c|c|}
\hline (b) & $\begin{array}{l}3.7 \\
3.4\end{array}$ & $\begin{array}{l}5.9 \\
3.4\end{array}$ & & $\begin{array}{l:l}9.2 & 9.2 \\
6.4 & 6.4\end{array}$ & & $\begin{array}{l:l}5.9 & 3.7 \\
3.4 & 3.4\end{array}$ & \\
\hline 22.4 & & & 22.6 & & 22.6 & & 22.4 \\
\hline 22.4 & & & 22.6 & & 22.6 & & 22.4 \\
\hline & 5.6 & 7.8 & & $\begin{array}{l:l}7.8 & 7.8 \\
\end{array}$ & & $\begin{array}{l:l}7.8 & 5.6\end{array}$ & \\
\hline & 3.5 & 3.5 & & $\begin{array}{l:l}3.5 & 3.5 \\
\end{array}$ & & $3.5: 3.5$ & \\
\hline 16.7 & & & 17.9 & & 17.9 & & 16.7 \\
\hline 16.7 & & & 17.9 & & 17.9 & & 16.7 \\
\hline & 5.8 & 8.2 & & $\begin{array}{l:l}8.2 & 8.2\end{array}$ & & 8.2 & \\
\hline & 3.5 & 3.9 & & $\begin{array}{l:l}3.9 & 3.9\end{array}$ & & 3.9 & \\
\hline 18.4 & & & 15.5 & & 15.5 & & 18.4 \\
\hline 18.4 & & & 15.5 & & 15.5 & & 18.4 \\
\hline & 6.4 & 7.8 & & 7.8 & & 7.8 & \\
\hline & 3.5 & 3.5 & & 3.5 & & 3.5 & \\
\hline 19.5 & & & 13.1 & & 13.1 & & 19.5 \\
\hline 19.5 & & & 13.1 & & 13.1 & & 19.5 \\
\hline
\end{tabular}

\begin{tabular}{|c|c|c|c|c|c|c|}
\hline (c) & $\begin{array}{l:l}44.3 & 124.0 \\
41.3 & 72.3 \\
\end{array}$ & & $\begin{array}{r:}194.0194 .0 \\
133.8133 .8 \\
\end{array}$ & & $\begin{array}{r:c}124.0 & 44.3 \\
72.3 & 41.3 \\
\end{array}$ & \\
\hline 35.1 & & 37.9 & & 37.9 & & 35.1 \\
\hline 35.1 & & 37.9 & & 37.9 & & 35.1 \\
\hline & $\begin{array}{l:l}67.6 & 163.3 \\
42.1 & 73.7 \\
\end{array}$ & 11 & \begin{tabular}{|l:l}
63.3 & 63.3 \\
73.7 & 73.7 \\
\end{tabular} & & $\begin{array}{r:l}163.3 & 67.6 \\
73.7 & 42.1 \\
\end{array}$ & \\
\hline 33.8 & & 31.0 & & 31.0 & & 33.8 \\
\hline 33.8 & & 31.0 & & 31.0 & & 33.8 \\
\hline & $\begin{array}{ll:l}69.6 & 173.1\end{array}$ & 1) & 173.1173 .1 & & 173.169 .6 & \\
\hline & $42.1: 80.9$ & & $\begin{array}{l:ll}80.9 & 80.9 \\
\end{array}$ & & $80.9: 42.1$ & \\
\hline 27.8 & & 25.1 & & 25.1 & & 27.8 \\
\hline 27.8 & & 25.1 & & 25.1 & & 27.8 \\
\hline & \begin{tabular}{|l:l}
77.2 & 163.3 \\
\end{tabular} & & 163.3163 .3 & & 163.377 .2 & \\
\hline & $\begin{array}{l:l}42.1 & 73.7\end{array}$ & & $\begin{array}{l:ll}73.7 & 73.7\end{array}$ & & $73.7: 42.1$ & \\
\hline 25.5 & & 19.9 & & 19.9 & & 25.5 \\
\hline 25.5 & & 19.9 & & 19.9 & & 25. \\
\hline
\end{tabular}

\begin{tabular}{|c|c|c|c|c|c|c|}
\hline (d) & \multicolumn{2}{|l|}{\begin{tabular}{l:l|}
12 & 21 \\
\end{tabular}} & \multicolumn{2}{|l|}{$\begin{array}{l:l}21 & 21 \\
\end{array}$} & \multicolumn{2}{|c|}{$21: 12$ जाII } \\
\hline 1.56 & & 1.67 & & 1.67 & & 1.56 \\
\hline 1.56 & & 1.67 & & 1.67 & & 1.56 \\
\hline & $\begin{array}{l:l}12 & 21\end{array}$ & & 21 & & $\begin{array}{l:l}21 & 12\end{array}$ & \\
\hline & $12: 21$ & & $\begin{array}{l:l}21 & 21 \\
\end{array}$ & & $21: 12$ & \\
\hline 2.02 & & 1.73 & & 1.73 & & 2.02 \\
\hline 2.02 & & $1.7 \overline{3}$ & & 1.73 & & 2.02 \\
\hline & $\begin{array}{l:l}12 & 21 \\
\end{array}$ & & $\begin{array}{l:l}21 & 21 \\
\end{array}$ & & $\begin{array}{l:l}21 & 12 \\
\end{array}$ & \\
\hline & $12: 21$ & & 21 & & $21: 12$ & \\
\hline 1.52 & & 1.62 & & 1.62 & & 1.52 \\
\hline 1.52 & & 1.62 & & 1.62 & & 1.52 \\
\hline & $\begin{array}{l:l}12 & 21 \\
\end{array}$ & & $\begin{array}{l:l}21 & 21\end{array}$ & & $\begin{array}{l:l}21 & 12\end{array}$ & \\
\hline & $12: 21$ & & $21: 21$ & & $21: 12$ & \\
\hline 1.31 & & 1.52 & & 1.52 & & 1.31 \\
\hline 1.31 & & 1.52 & & 1.52 & & 1.31 \\
\hline
\end{tabular}

Fig. 7 Properties of plastic hinges of models P1 and P1-W: a Nominal flexural strength (kN m); b curvature at yielding $(1 / \mathrm{km}) ; \mathbf{c}$ ultimate curvature $(1 / \mathrm{km})$; $\mathbf{d}$ curvature ductility

hysteretic model implemented in IDARC, which is characterized by the moment-curvature envelope and three parameters that govern strength degradation, stiffness degradation and pinching effect. For the plastic hinges located on the beams, a bilinear moment-curvature envelope curve was adopted. The values of the parameters that define this envelope and those that control the strength degradation, the stiffness degradation and the pinching effect were determined from the results of prior static and dynamic tests conducted by BenaventCliment (2007) and Benavent-Climent et al. (2009, 2010). The polygonal hysteretic model implemented in IDARC was also used for modelling the hysteretic behaviour of the plastic hinges of the columns. Their flexural strength, yield curvature and ultimate curvature were determined with the program Response-2000, taking into account the effect of axial forces (Bentz and Collins 2000). The parameters that control the hysteretic behaviour of the plastic hinges in the columns were calibrated with the results of experiments conducted by Sezen and Moehle (2006). For illustrative purposes, Figs. 7 and 8 show the nominal flexural strength, curvature at yielding, ultimate curvature and curvature ductility at the end sections of the members for the central frames of prototypes P1-W and P2-W, respectively. In the figures, the shaded cells represent the rigid joints. The square cells above and below the shaded cells represent the columns. The rectangular cells at the left and right sides of the shaded cells represent the beams. Within each square cell representing a column there are two numbers. The upper one corresponds to the top end and the lower one to the bottom end of the column. Within each rectangular cell representing a beam there are four numbers. The ones closest to the upper-left and lower-left corners of the cell correspond to the left end of the beam 

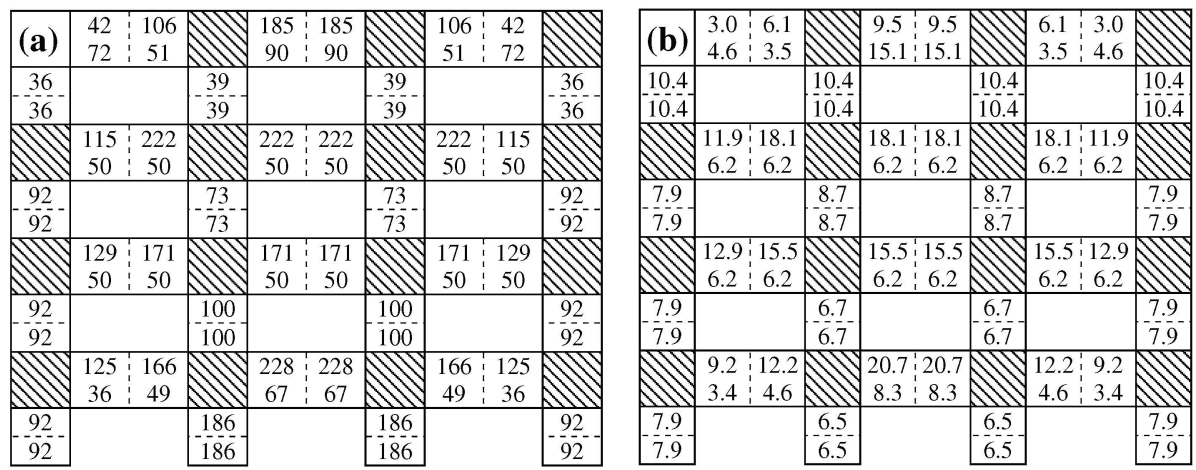

\begin{tabular}{|c|c|c|c|c|c|c|}
\hline (c) & $\begin{array}{l:l}36.2 & 128.0 \\
55.0 & 74.1\end{array}$ & & \begin{tabular}{|l:l}
200.0 & 200.0 \\
317.1 & 317.1
\end{tabular} & & $\begin{array}{r:l}128.0 & 36.2 \\
74.1 & 55.0\end{array}$ & \\
\hline 20.2 & & 26.9 & & 26.9 & & 20.2 \\
\hline 20.2 & & 26.9 & & 26.9 & & 20.2 \\
\hline NII & $143.0 ; 380.1$ & & $380.1 ; 380.1$ & & $380.1: 143.0$ & \\
\hline & $74.8: 131.0$ & & 131.01131 .0 & & $131.0,74.8$ & \\
\hline 22.4 & & 22.4 & & 22.4 & & 22.4 \\
\hline 22.4 & & 22.4 & & 22.4 & & 22.4 \\
\hline 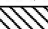 & 155.0325 .5 & & $\sqrt{325.5} 325.5$ & & 325.511550 & \\
\hline & $74.8: 131.0$ & & 131.0131 .0 & & $131.0,74.8$ & \\
\hline 20.3 & & 13.1 & & 13.1 & & 20.3 \\
\hline 20.3 & & 13.1 & & 13.1 & & 20.3 \\
\hline & $110.0 ; 256.2$ & & 434.7434 .7 & & 256.2110 .0 & \\
\hline & \begin{tabular}{|l:l}
41.3 & 96.4 \\
\end{tabular} & & $175: 175$ & & $96.4: 41.3$ & \\
\hline 20.4 & & 15.3 & & 15.3 & & 20.4 \\
\hline 20.4 & & 15.3 & & 15.3 & & 20.4 \\
\hline
\end{tabular}

\begin{tabular}{|c|c|c|c|c|c|c|}
\hline (d) & $\begin{array}{l:l}12 & 21 \\
\end{array}$ & (1/1) & \multicolumn{2}{|l|}{$\begin{array}{c:c}21 & 21\end{array}$} & \multicolumn{2}{|l|}{$\begin{array}{l:l}21 & 12 \\
\end{array}$} \\
\hline 1.94 & & 2.59 & & 2.59 & & 1.94 \\
\hline 1.94 & & 2.59 & & 2.59 & & 1.94 \\
\hline & $\begin{array}{l:l}12 & 21\end{array}$ & & $\begin{array}{l:l}21 & 21\end{array}$ & & $\begin{array}{c:c} & 12\end{array}$ & \\
\hline & $\begin{array}{l:l}12 & 21 \\
\end{array}$ & & $\begin{array}{lll}21 & 21 \\
\end{array}$ & & $\begin{array}{l:l}21 & 12\end{array}$ & \\
\hline 2.85 & & 2.59 & & 2.59 & & 2.85 \\
\hline 2.85 & & 2.59 & & 2.59 & & 2.85 \\
\hline & $\begin{array}{c:c}12 \\
12\end{array}$ & & $\begin{array}{l:l}21 & 21\end{array}$ & & $\begin{array}{l:l}21 & 12\end{array}$ & \\
\hline & $\begin{array}{l:l}12 & 21 \\
\end{array}$ & & \begin{tabular}{l|l}
21 & 21 \\
\end{tabular} & & $\begin{array}{l:l}21 & 12 \\
\end{array}$ & \\
\hline 2.60 & & 1.94 & & 1.94 & & 2.60 \\
\hline 2.60 & & 1.94 & & 1.94 & & 2.60 \\
\hline & $\begin{array}{l:l}12 & 21\end{array}$ & & $\begin{array}{l:l}21 & 21\end{array}$ & & $\begin{array}{l:l}21 & 12\end{array}$ & \\
\hline & $\begin{array}{l:l}12 & 21 \\
\end{array}$ & & \begin{tabular}{l|l}
21 & 21 \\
\end{tabular} & & $\begin{array}{l:l}21 & 12 \\
\end{array}$ & \\
\hline 2.60 & & 2.36 & & 2.36 & & 2.60 \\
\hline 2.60 & & 2.36 & & 2.36 & & 2.60 \\
\hline
\end{tabular}

Fig. 8 Properties of plastic hinges of models P2 and P2-W: a Nominal flexural strength (kN m); b curvature at yielding $(1 / \mathrm{km})$; $\mathbf{c}$ ultimate curvature $(1 / \mathrm{km})$; $\mathbf{d}$ curvature ductility

under negative and positive bending, respectively. The numbers closest to the upper-right and lower-right corners of the cell respectively correspond to the right end of the beam under negative and positive bending. The masonry infill walls were represented with diagonal struts. The hysteretic behaviour of the infill walls was idealized with the modified Bouc-Wen model (Bouc 1967; Baber and Noori 1985) implemented in the IDARC 6.1 code. The lateral yield strength and the initial lateral stiffness of the infill walls were determined from the test conducted by Pujol et al. (2008). These test were likewise used to calibrate the modified Bouc-Wen model so that it captures relevant aspects of the cyclic behaviour (strength and stiffness degradation and pinching effect. Since one of the objectives of this study was to determine the influence of the masonry infill walls, two additional numerical models referred to as P1 and P2 hereafter were developed by removing the infill walls from models P1-W and $\mathrm{P} 2-\mathrm{W}$, respectively. Thus, models $\mathrm{P} 1$ and $\mathrm{P} 2$ are identical to $\mathrm{P} 1-\mathrm{W}$ and $\mathrm{P} 2-\mathrm{W}$, except that they do not have infill walls.

\section{Pushover analyses}

The periods $T_{n}$, mode-shape vectors $\phi_{\mathrm{n}}$, participation factors $\Gamma_{\mathrm{n}}=\boldsymbol{\phi}_{\mathrm{n}}^{\mathrm{T}} \mathbf{M} \mathbf{1} /\left(\boldsymbol{\phi}_{\mathrm{n}}^{\mathrm{T}} \mathbf{M} \boldsymbol{\phi}_{\mathrm{n}}^{\mathrm{T}}\right)$ (here $\mathbf{M}$ is the mass matrix and $\mathbf{1}$ is a vector of ones) and generalized masses $m_{n}$ of the prototype buildings for each vibration mode $n$ were obtained through eigenvalue analyses conducted with the numerical models of Sect. 5.2. It was assumed that the masses are concentrated 
Table 1 Dynamic properties of the prototypes

\begin{tabular}{|c|c|c|c|c|c|c|c|c|c|c|c|c|}
\hline \multirow[t]{2}{*}{ Mode $n$} & \multicolumn{3}{|l|}{$\mathrm{P} 1$} & \multicolumn{3}{|l|}{$\mathrm{P} 2$} & \multicolumn{3}{|l|}{ P1-W } & \multicolumn{3}{|l|}{$\mathrm{P} 2-\mathrm{W}$} \\
\hline & $n=1$ & $n=2$ & $n=3$ & $n=1$ & $n=2$ & $n=3$ & $n=1$ & $n=2$ & $n=3$ & $n=1$ & $n=2$ & $n=3$ \\
\hline$T_{n}(s)$ & 1.33 & 0.46 & 0.27 & 1.41 & 0.45 & 0.24 & 0.73 & 0.18 & 0.10 & 0.72 & 0.18 & 0.10 \\
\hline$\Gamma_{n}$ & 1.00 & 0.31 & 0.15 & 0.99 & 0.34 & 0.19 & 1.05 & 0.09 & 0.02 & 1.06 & 0.10 & 0.03 \\
\hline$\phi_{4, n}$ & 1.29 & -1.23 & 0.76 & 1.31 & -1.23 & 0.73 & 1.04 & -1.22 & 0.98 & 1.03 & -1.19 & 0.99 \\
\hline$\phi_{3, n}$ & 1.08 & 0.18 & -1.33 & 1.08 & 0.26 & -1.28 & 1.00 & -0.43 & -0.95 & 1.00 & -0.46 & -0.84 \\
\hline$\phi_{2, n}$ & 0.79 & 1.07 & 0.03 & 0.75 & 1.10 & 0.11 & 0.92 & 0.62 & -0.87 & 0.91 & 0.60 & -0.95 \\
\hline$\phi_{1, n}$ & 0.44 & 0.96 & 1.10 & 0.38 & 0.89 & 1.13 & 0.81 & 1.25 & 0.98 & 0.79 & 1.25 & 0.97 \\
\hline
\end{tabular}

in each story and each mass has a SDOF (horizontal translation). Next, a nonlinear static pushover analysis with displacement control was performed for each of the $N$ modes of vibration using the lateral load pattern $\mathbf{M} \phi_{\mathrm{n}} s$ (here, $s$ is a scalar factor), until one of the stories reached its ultimate displacement capacity. These calculations provided the shear force-interstory drift curve $Q_{n, i}-\delta_{n, i}$ of each story $i$ and for each mode of vibration $n$. In addition, at each load step of each pushover analysis, the generalized force $Q_{\mathrm{n}}=\phi_{\mathrm{n}}^{\mathrm{T}} \mathbf{M} \phi_{\mathrm{n}} s$ and the corresponding generalized displacement $v_{\mathrm{n}}=\left(\phi_{\mathrm{n}}^{\mathrm{T}} \mathbf{M v}\right) /\left(\phi_{\mathrm{n}}^{\mathrm{T}} \mathbf{M} \phi_{\mathrm{n}}\right)$ associated with a given mode of vibration $n$ were calculated. Here, $\mathbf{v}$ is the lateral displacement vector resulting from applying the load vector $\mathbf{M} \phi_{\mathbf{n}} s$. The values of $T_{n}, \Gamma_{n}$ and the components $\phi_{i, n}$ of vector $\phi_{n}$ for the four prototypes investigated are summarized in Table 1, for the first 3 modes of vibration.

In models $\mathrm{P} 1-\mathrm{W}$ and $\mathrm{P} 2-\mathrm{W}$, the infill walls work in parallel with the $\mathrm{RC}$ frames, and it is possible to evaluate the contribution of each part separately (the bare frame and the infill walls) to the total lateral shear force of the story. Among the different $Q_{n, i}-\delta_{n, i}$ curves obtained from the pushover analyses conducted for each mode of vibration $n$, the one that reached the largest interstory drift $\delta_{n, i}$ was selected. With the selected curve, a bilinear equivalent envelope curve was obtained by applying the procedure proposed by Newmark and Hall (1982). This bilinear approximation allows for determining the yield lateral strength $Q_{y i}$, the yield displacement $\delta_{y i}$, and the ultimate displacement $\delta_{u i}$ of the $i$ th story. For the bare RC frame $\delta_{u i}$ was determined as the inter-story drift beyond which the lateral shear force drops below $20 \%$ of the maximum value attained in the pushover curve. As for the infill panels, the $\delta_{u i}$ corresponding to a ductility factor $\mu=3$ was adopted on the basis of previous work by Dolsek and Fajfar (2008). The corresponding values obtained are summarized in Tables 2 and 3, where the subscripts $w$ and $r c$ refer to the infill walls and to the bare RC frames, respectively, and the subindex $i$ to the story. In these Tables, the ductility factor defined with Eq. (1) and calculated for each story $i$ from the envelope curve $Q_{y i}-\delta_{y i}$ of the bare RC frame $r_{c} \mu$ is also shown. As can be seen in Tables 2 and 3 , in some stories the actual ductility factor $r_{c} \mu$ obtained from the pushover analyses is slightly below the value 2 prescribed by the Spanish codes and adopted for designing the prototypes.

\section{Expected damage on the buildings predicted using the energy-based seismic index method}

The susceptibility of a structure to damage when subjected to an earthquake of a given severity can be assessed through the energy-based seismic index method proposed by Benavent- 
Table 2 Results of the pushover analyses for models P1 and P1-W

\begin{tabular}{|c|c|c|c|c|c|c|c|}
\hline \multirow[t]{2}{*}{ Story } & \multicolumn{4}{|c|}{ Bare frames of model P1 } & \multicolumn{3}{|c|}{ Infill walls of model P1-W } \\
\hline & $r c \delta_{y i}(\mathrm{~mm})$ & ${ }_{r c} \delta_{u i}(\mathrm{~mm})$ & $r c \mu$ & $r_{c} Q_{y i}(\mathrm{kN})$ & $w_{y i}(\mathrm{~mm})$ & $w \delta_{u i}(\mathrm{~mm})$ & $w Q_{y i}(\mathrm{kN})$ \\
\hline 4 & 19.97 & 35.81 & 1.79 & 644 & 5.73 & 23.07 & 2,772 \\
\hline 3 & 17.72 & 36.71 & 2.07 & 778 & 5.72 & 23.05 & 2,773 \\
\hline 2 & 17.82 & 37.52 & 2.11 & 996 & 5.59 & 23.01 & 2,775 \\
\hline 1 & 24.91 & 39.89 & 1.60 & 1,074 & 5.59 & 23.02 & 396 \\
\hline
\end{tabular}

Table 3 Results of the pushover analyses for models P2 and P2-W

\begin{tabular}{|c|c|c|c|c|c|c|c|}
\hline \multirow[t]{2}{*}{ Story } & \multicolumn{4}{|c|}{ Bare frames of model $\mathrm{P} 2$} & \multicolumn{3}{|c|}{ Infill walls of model P2-W } \\
\hline & ${ }_{c} \delta_{y i}(\mathrm{~mm})$ & $r c \delta_{u i}(\mathrm{~mm})$ & $r c \mu$ & ${ }_{r c} Q_{y i}(\mathrm{kN})$ & $w^{\delta_{y i}}(\mathrm{~mm})$ & ${ }_{w} \delta_{u i}(\mathrm{~mm})$ & ${ }_{w} Q_{y i}(\mathrm{kN})$ \\
\hline 4 & 13.19 & 26.32 & 2.00 & 497 & 5.71 & 23.01 & 2,663 \\
\hline 3 & 18.65 & 30.57 & 1.64 & 768 & 5.72 & 23.02 & 2,663 \\
\hline 2 & 21.96 & 36.18 & 1.65 & 819 & 5.72 & 23.01 & 2,663 \\
\hline 1 & 17.61 & 33.08 & 1.88 & 886 & 5.84 & 22.98 & 380 \\
\hline
\end{tabular}

Climent $(2011 \mathrm{a}, \mathrm{b})$. The method characterizes the damage potential of the ground motion by a function $f_{A}$ that defines the normalized energy input spectral shape, by a function $f_{h}$ that relates the hysteretic energy $E_{h}$ to the total input energy $E$, and by a Seismic Hazard Energy Factor $\left(A E_{I}\right)$ (Decanini and Mollaioli 1998) that represents the area under the energy input spectrum per unit mass between 0.05 and $4 \mathrm{~s}$ :

$$
A E_{I}=\int_{0.05}^{4} \frac{E}{M} d T
$$

Following Decanini and Mollaioli (2001) approach, $f_{A}, f_{h}$ can be assumed to depend only on the fundamental period $(T)$ and on the ductility $\mu$ of the system, and thus the total input energy per unit mass $E / M$, and the ratio of hysteretic energy $E_{h}$ to total input energy $E$ be written as follows:

$$
\begin{aligned}
E / M & =f_{A}(\mu, T) A E_{I} \\
E_{h} / E & =f_{h}(\mu, T)
\end{aligned}
$$

The earthquake resistance of the structure, hence its susceptibility to damage, is a function of two counterpart energy factors, $A E_{I S}$ and $A E_{I U} . A E_{I S}$ represents the level of the maximum earthquake that the structure can sustain within the elastic range. $A E_{I U}$ is associated with the ultimate earthquake that the structure can sustain, that is, $A E_{I U}$ is the level of ground motion that would drive the structure to the brim of collapse. Factors $A E_{I}, A E_{I S}$ and $A E_{I U}$ can be related by a seismic index $I_{v}$ that is defined as follows:

$$
\begin{array}{ll}
\text { if } A E_{I} \leq A E_{I S}: & I_{V}=0 \\
\text { if } A E_{I S}<A E_{I}<A E_{I U}: & I_{V}=\frac{\left(A E_{I}-A E_{I S}\right)}{\left(A E_{I U}-A E_{I S}\right)} \\
\text { if } A E_{I} \geq A E_{I U}: & I_{V}=1
\end{array}
$$


The functions $f_{A}, f_{h}$ and the value $A E_{I}$ at a given site can be estimated by synthesizing the energy input spectrum obtained for a large number of earthquake records as Decanini and Mollaioli (1998) did. In this case the index $I_{V}$ represents the seismic vulnerability of the structure under a potential future earthquake. In the present study, the energy-based seismic index method proposed by Benavent-Climent (2011a) is applied using the spectral shapes $f_{A}, f_{h}$ and the value of $A E_{I}$ obtained for a single ground motion-the main shock of the Lorca earthquake. In this case, the index $I_{V}$ can be interpreted as the expected level of damage on the building under this particular ground motion.

By applying the energy-based seismic index method, the values of $A E_{I S}$ and $A E_{I U}$ for the structures represented with the numerical models described in Sect. 5 can be obtained by the following procedure (Benavent-Climent 2011a,b) that idealizes the building with a lumped mass system with one degree of freedom (horizontal translation) per mass:

1) Use the shear force-interstory drift curve $Q_{n, i}-\delta_{n, i}$ obtained from the pushover analysis for each mode of vibration $n$ :

a) Calculate the secant stiffness $k_{n, i}$ at $60 \%$ of the maximum strength $Q_{n, i}^{\max }$, the yielding displacement $\delta_{n y, i}=Q_{n, i}^{\max } / k_{n, i}$ and calculate the maximum amount of elastic strain energy $E_{S, i}^{\max }$ that a given story $i$ can store with the following expression which is defined as the maximum of $k_{n, i} \delta_{n, i}^{2} / 2$ among the $N$ modes, that is:

$$
E_{S, i}^{\max }=\max \left\{\frac{k_{n, i} \delta_{n y, i}^{2}}{2}\right\}
$$

b) Calculate the plastic strain energy $E_{h m n, i}^{u}$ dissipated by each story $i$ until it attains its ultimate displacement capacity for each mode of vibration $n$, and then obtain $E_{h m, i}^{u}$ which is defined as the maximum of $E_{h m n, i}^{u}$ among the $N$ modes, that is:

$$
E_{h m, i}^{u}=\max \left\{E_{h m n, i}^{u}\right\}
$$

2) Select the first $r$ modes of vibration ( $r=1$ or 2 is commonly enough to get a good approximation) and, using the results of the pushover analyses, for each $r$ th, mode, and:

a) Calculate the plastic strain energy dissipated in the $i$ th story until any story $j$ attains its ultimate lateral displacement capacity, $E_{h m n, i}$; next, obtain the plastic strain energy distribution vector $\psi_{n}$ whose components $\psi_{n i}$, for a given vibration mode $n$ and for each story $i$, are given by:

$$
\psi_{n, i}=\frac{E_{h m n, i}}{\sum_{k=1}^{N} E_{h m n, k}}
$$

Vector $\psi_{n}$ obtained for the first vibration mode, $\psi_{1}$, and for the four models investigated is shown in the column "Pushover analysis" of Table 4. This vector contains the prediction of how the plastic strain energy (i.e. the structural damage) will be distributed among the stories. Vector $\psi_{n}$ captures the possibility of damage concentration in a given story. The fact that $\psi_{1 i}$ in the first story is markedly larger than in the rest of the stories anticipates severe concentration of damage in the first story. This concentration is extremely severe in the models with infill walls P1-W and P2-W.

b) Calculate the ductility factor $\mu_{n}\left(=v_{n, u} / v_{n, y}\right)$ associated with each mode of vibration $n$ from the generalized force-displacement curve, $Q_{n}-v_{n}$, obtained in the pushover analyses. Here, $v_{n, u}$ is the maximum value attained by $v_{n}$, and $v_{n, y}$ is the generalized 
Table 4 Plastic strain energy distribution vector for vibration mode $1\left(\Psi_{1}\right)$

\begin{tabular}{|c|c|c|c|c|c|c|c|c|c|}
\hline \multirow[t]{2}{*}{ Story } & \multirow[t]{2}{*}{$\psi_{1, i}$} & \multicolumn{2}{|l|}{$\mathrm{P} 1$} & \multicolumn{2}{|l|}{$\mathrm{P} 2$} & \multicolumn{2}{|l|}{ P1-W } & \multicolumn{2}{|l|}{$\mathrm{P} 2-\mathrm{W}$} \\
\hline & & $\begin{array}{l}\text { Pushover } \\
\text { analysis }\end{array}$ & $\begin{array}{l}\text { Dynamic } \\
\text { analysis }\end{array}$ & $\begin{array}{l}\text { Pushover } \\
\text { analysis }\end{array}$ & $\begin{array}{l}\text { Dynamic } \\
\text { analysis }\end{array}$ & $\begin{array}{l}\text { Pushover } \\
\text { analysis }\end{array}$ & $\begin{array}{l}\text { Dynamic } \\
\text { analysis }\end{array}$ & $\begin{array}{l}\text { Pushover } \\
\text { analysis }\end{array}$ & $\begin{array}{l}\text { Dynamic } \\
\text { analysis }\end{array}$ \\
\hline 4 & $\psi_{1,4}$ & 0.04 & 0.14 & 0.02 & 0.08 & 0.00 & 0.00 & 0.00 & 0.00 \\
\hline 3 & $\psi_{1,3}$ & 0.15 & 0.21 & 0.10 & 0.21 & 0.00 & 0.00 & 0.00 & 0.00 \\
\hline 2 & $\psi_{1,3}$ & 0.29 & 0.21 & 0.26 & 0.19 & 0.02 & 0.04 & 0.03 & 0.07 \\
\hline 1 & $\psi_{1,1}$ & 0.51 & 0.44 & 0.62 & 0.52 & 0.98 & 0.96 & 0.97 & 0.93 \\
\hline
\end{tabular}

Table 5 Ductility factors and parameters that define the spectral shapes

\begin{tabular}{llllllll}
\hline Mode $r$ & $\mathrm{P} 1$ & & & $\mathrm{P} 2$ & & $\mathrm{P} 1-\mathrm{W}$ & $\mathrm{P} 2-\mathrm{W}$ \\
\cline { 2 - 3 } & $r=1$ & $r=2$ & & $r=1$ & $r=2$ & $r=1$ & $r=1$ \\
\hline$T_{r}(s)$ & 1.33 & 0.46 & 1.41 & 0.45 & 0.73 & 0.72 \\
$\mu_{r}$ & 1.36 & 1.38 & 1.44 & 1.36 & 1.93 & 1.87 \\
$f_{E}\left(T_{r}\right)=f_{A}\left(T_{r}, 1\right)$ & 0.35 & 1.46 & 0.32 & 1.40 & 0.55 & 0.60 \\
$f_{A}\left(T_{r}, \mu_{r}\right)$ & 0.18 & 1.05 & 0.17 & 1.05 & 0.45 & 0.49 \\
$f_{h}\left(T_{r}, \mu_{r}\right)$ & 0.58 & 0.60 & 0.57 & 0.59 & 0.65 & 0.66 \\
\hline
\end{tabular}

displacement at yielding. The values of $\mu_{n}$ determined in this way for $r=1$ and $r=2$ are shown in Table 5 .

3) Determine the ordinates $f_{E}\left(T_{n}\right), f_{A}\left(T_{n}, \mu_{n}\right)$ and $f_{h}\left(T_{n}, \mu_{n}\right)$ for each of the $r$ modes of vibration considered, using the spectral shapes of the Lorca earthquake. Here, $f_{E}$ is the function $f_{A}$ for $\mu=1$, that is, $f_{E}(T)=f_{A}(T, 1)$. The corresponding values for each mode $r$ are shown in Table 5 .

4) Substitute the above parameters in the following expressions to obtain $A E_{I S}$ and $A E_{I U}$ :

$$
\begin{aligned}
& A E_{I S}=\min \left\{\frac{E_{S, i}^{\max }}{\sum_{n=1}^{r} \psi_{S n, i} \Gamma_{n}^{2} m_{n} f_{E}\left(T_{n}\right)}\right\} \\
& A E_{I U}=\min \left\{\frac{2 a_{h i} b_{h i} E_{h m, i}^{u}}{\sum_{n=1}^{r} \psi_{n, i} \Gamma_{n}^{2} m_{n} f_{h}\left(\mu_{n}, T_{n}\right) f_{A}\left(\mu_{n}, T_{n}\right)}\right\}
\end{aligned}
$$

In Eq. (20), the ratio $a_{h i}$ represents the increase in plastic strain energy due to cyclic reversals of deformation with respect to the value that would be obtained by applying the load monotonically. The ratio $b_{h i}$ indicates the extent to which the plastic strain deformation is biased towards the positive or negative domain. For RC frames with wide beams, the values $a_{h i}=1.5$ and $b_{h i}=0.75$ proposed in past research (Benavent-Climent et al. 2004) can be adopted. Later, in Sect. 8, the validity of these values for $a_{h i}$ and $b_{h i}$ is further corroborated through nonlinear dynamic response analyses. In Eq. (19), $\psi_{S n}$ is a vector that expresses the distribution of the elastic strain energy among the stories in mode $n$, and its components $\psi_{S n, i}=E_{S n, i} / \sum_{k=1}^{N} E_{S n, k}$ are calculated by:

$$
\psi_{S n, i}=\frac{k_{n, i}\left(\phi_{i, n}-\phi_{(i-1), n}\right)^{2}}{\sum_{j=1}^{N} k_{n, j}\left(\phi_{j, n}-\phi_{(j-1), n}\right)^{2}}
$$



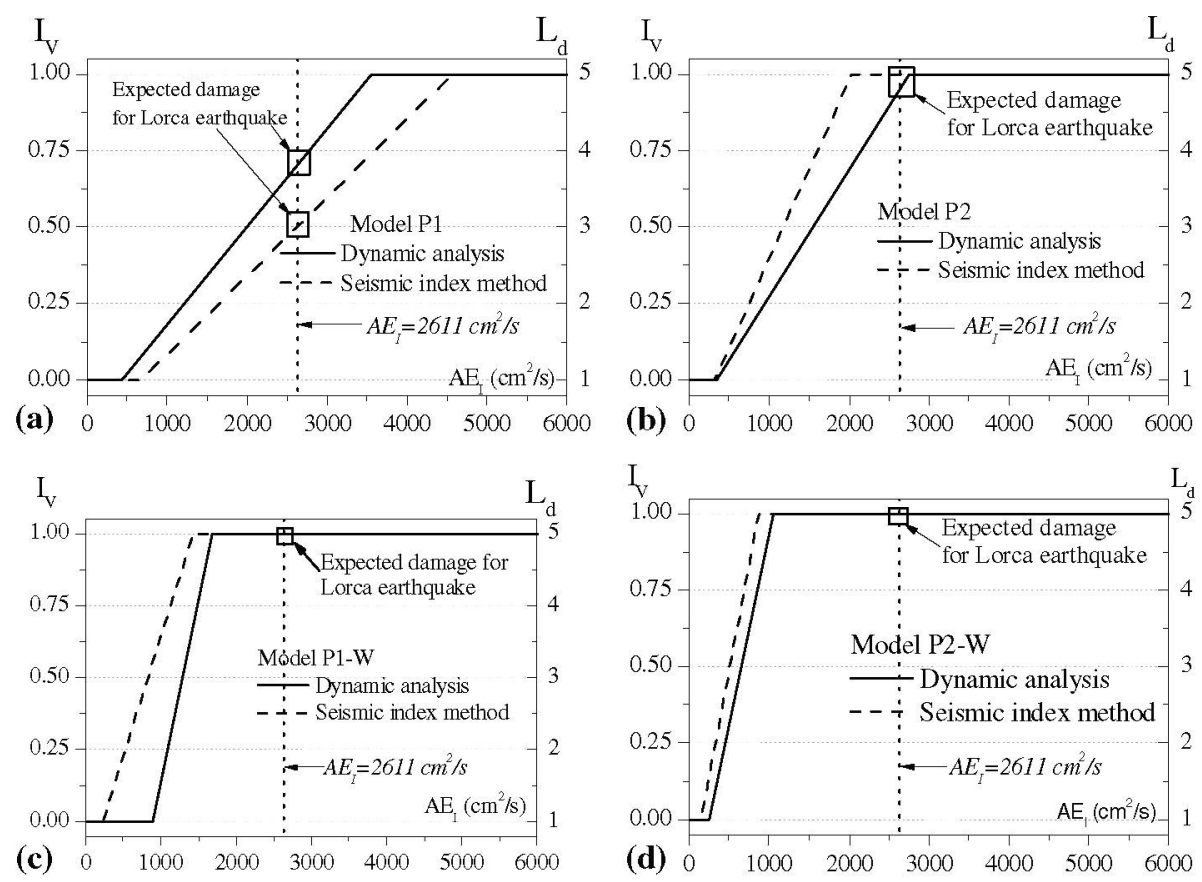

Fig. 9 Vulnerability curves and expected damage for Lorca earthquake for models: a P1, b P2, c P1-W, d $\mathrm{P} 2-\mathrm{W}$

In Eqs. (19) and (20), the term within brackets must be computed for each story and the minimum value among the stories must be adopted. A more detailed explanation of the above steps can be found in Benavent-Climent (2011a,b). Once $A E_{I, S}$ and $A E_{I, U}$ are determined from Eqs. (19) and (20), the relation between the seismic index factor $I_{v}$ and $A E_{I}$ given by Eqs. (13) to (15) can be plotted in the $I_{v}-A E_{I}$ plane, as shown with dashed lines in Fig. 9. We should stress that these dashed lines represent the "vulnerability curve" of the prototypes investigated under a ground motion whose normalized energy-input spectral shape $f_{A}$ and hysteretic to input energy ratio $f_{h}$ are the ones calculated with the accelerogram of the Lorca earthquake. The vertical line plot in the figures of abscissa $A E_{I}=2611 \mathrm{~cm}^{2} / \mathrm{s}$ corresponds to the energy input by the Lorca earthquake. The ordinate of the intersection point of this vertical line with the "vulnerability curves" indicates the level of structural damage expected in the prototype structures under the Lorca earthquake in terms of index $I_{v}$ (left vertical axis), which evaluates damage in the range $I_{v}=1$ (no damage) to $I_{v}=1$ (on the brim of collapse). The right vertical axis of the plot of Fig. 9 shows the damage degree $L_{d}$ defined by the European macroseismic scale (Scales 1998), which ranges from $L_{d}=1$ (no damage) to $L_{d}=5$ (complete destruction). Past studies (Benavent-Climent 2011a,b) showed that $I_{v}$ and $L_{d}$ are well correlated.

From Fig. 9 it follows that the prototype buildings with infill walls designed according to codes in force in both periods of time, 1994-2002 and 2003-2008 (models P1-W and P2-W), could be clearly expected to collapse $\left(I_{v}>1\right)$ under the Lorca earthquake. The prototype building without infill walls built according to the codes in force in the period 1994-2002 (model P1) was expected to experience moderate to severe damage (quantified as $I_{v}=0.5$ or $L_{d}=3$ ), while those built with the codes in force in the period 2003-2008 (model P2) 
were expected to collapse. Since all the actual buildings in Lorca had infill walls, models P1 and $\mathrm{P} 2$ do not represent real buildings, but the comparison of their damage with the damage suffered by the prototypes with infill walls underlines the negative influence of infill walls in the overall seismic response of the structure. This negative influence is enhanced by an inappropriate distribution of the walls among the stories, which jeopardizes the distribution of the plastic strain energy among the stories, and causes the damage to be concentrated in the first story.

\section{Nonlinear dynamic response analyses}

\subsection{Values of $\mathrm{AE}_{I S}$ and $\mathrm{AE}_{I U}$}

The expected damage predicted in Sect. 7 with the energy-based seismic index method was further investigated through nonlinear dynamic response analyses using the Lorca earthquake as the input ground motion. More precisely, the values of $A E_{I S}$ and $A E_{I U}$ estimated in Sect. 7 from the results of nonlinear pushover analyses are recalculated in this section, through an incremental dynamic analysis (IDA) procedure (Vamvatsikos and Cornell 2002). In this procedure, the models are subjected to the ground motion, then scaled to multiple levels of increasing intensity (in terms of PGA), thus producing one curve of response parameterized versus intensity level. In this study, the response parameter used to define the curve is the base shear and level of intensity of the ground motion in terms of PGA, augmented in small increments of $0.005 \mathrm{~g}$. By applying the IDA procedure, two values of $P G A$ were obtained for each prototype. The first value, $P G A_{S}$, represents the intensity of the ground motion that triggers the occurrence of the first plastic hinge on the frame. The second value, $P G A_{U}$, represents the intensity that drives the structure to the brim of collapse. The distribution of plastic strain energy among the stories when the frame is on the brim of collapse is indicated in the column "Dynamic analysis" of Table 4 . The model was assumed to collapse when the base shear drops more than $20 \%$ of the maximum value attained in the aforementioned curve, or when a small increment of $P G A$ (of $0.005 \mathrm{~g}$ ) meant a drastic increase of the inter-story drift. The $P G A$ of the Lorca earthquake was $0.36 \mathrm{~g}$ and $A E_{I}=2611 \mathrm{~cm}^{2} / \mathrm{s}$, as indicated above.

Since the energy input by the earthquake in an elastic system is proportional to the square of the ground acceleration, once $P G A_{S}$ and $P G A_{U}$ are determined, the corresponding values of $A E_{I S}$ and $A E_{I U}$ are simply $A E_{I S}=2,611 \times\left(P G A_{S} / 0.36 \mathrm{~g}\right)^{2}$ and $A E_{I U}=$ $2,611 \times\left(P G A_{U} / 0.36 \mathrm{~g}\right)^{2}$. The $I_{V}-A E_{I}$ curves obtained by substituting the $A E_{I S}$ and $A E_{I U}$ obtained directly from nonlinear dynamic response analyses in Eqs. (13) to (15) are drawn with solid lines in Fig. 9. The "vulnerability curves" obtained with the IDA procedure are seen to be reasonably close to the ones estimated with the energy-based seismic index method that adopts the results of pushover analyses. The proximity of the results is basically due to the fact that the energy-based seismic index method: (1) predicts reasonably well the plastic strain energy distribution among the stories (compare the columns "Pushover analysis" and "Dynamic analysis" in Table 4); and (2) the values of parameters $a_{h i}$ and $b_{h i}$ calibrated in past research $\left(a_{h i}=1.5, b_{h i}=0.75\right)$ for the structural typology under study are very close to those obtained with the nonlinear dynamic response analyses, which are shown in Table 6 for each story. Finally, it is worth emphasizing that in the design of the $\mathrm{RC}$ bare frames, the infill panels were not considered as structural elements. However, the contribution of the infill walls to the lateral strength, stiffness and in general to the hysteretic behaviour of the buildings has been considered in the nonlinear dynamic response analyses. 
Table 6 Parameters $a_{h i}$ and $b_{h i}$

\begin{tabular}{|c|c|c|c|c|c|c|c|c|}
\hline \multirow[t]{2}{*}{ Story } & \multicolumn{2}{|l|}{$\mathrm{P} 1$} & \multicolumn{2}{|l|}{$\mathrm{P} 2$} & \multicolumn{2}{|c|}{ P1-W } & \multicolumn{2}{|c|}{$\mathrm{P} 2-\mathrm{W}$} \\
\hline & $a_{h i}$ & $b_{h i}$ & $a_{h i}$ & $b_{h i}$ & $a_{h i}$ & $b_{h i}$ & $a_{h i}$ & $b_{h i}$ \\
\hline 4 & 1.49 & 0.97 & 1.61 & 0.88 & - & - & - & - \\
\hline 3 & 1.34 & 0.69 & 1.41 & 0.70 & - & - & - & - \\
\hline 2 & 1.38 & 0.82 & 1.58 & 0.71 & 1.31 & 0.66 & 1.30 & 0.75 \\
\hline 1 & 1.44 & 0.71 & 1.54 & 0.74 & 1.32 & 0.65 & 1.43 & 0.61 \\
\hline
\end{tabular}

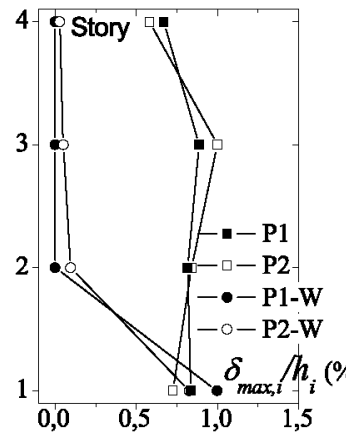

(a)

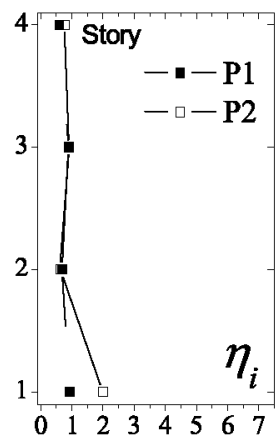

(b)

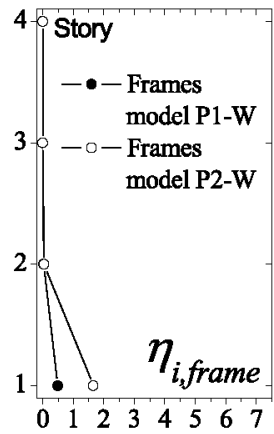

(c)

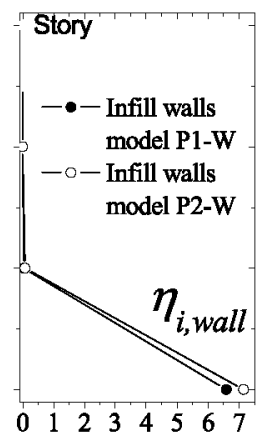

(d)

Fig. 10 Distributions of: a Inter-story drift; $\mathbf{b} \eta_{i}$ in bare frames P1, P2; $\mathbf{c} \eta_{i}$ in the frames of the prototypes $\mathrm{P} 1-\mathrm{W}, \mathrm{P} 2-\mathrm{W} ; \mathbf{d} \eta_{i}$ in the infill walls of the prototypes P1-W, P2-W

\subsection{Damage at the story level}

To investigate the damage at the story level, nonlinear time history analyses were carried out with the numerical models by subjecting them to two accelerograms. The first one corresponds to the first shock of the Lorca earthquake. The second accelerogram was built by merging the first and the second (main) shocks. The response under the first accelerogram provided information on the level of damage at the onset of the main shock, which occurred about 45 min later. The energy input spectrum of the first shock is much lower than that of the second one, as depicted in Fig. 1b, although the shapes are similar. The results of the nonlinear dynamic response analyses show that the prototypes experienced minor damage after the first earthquake: cracking occurred on the structural members at the first floor level, inter-story drifts remained below the limit associated with the inception of yielding, and no damage occurred on the infill panels. Thus, the second earthquake was responsible for the damage experienced by the structures that is discussed hereafter.

The maximum inter-story drift $\delta_{\max , i}$ normalized by the story height $h_{i}$ has been commonly used as an indicator of damage. The inter-story drift ratios $\delta_{\max , i} / h_{i}$ of the prototypes investigated are shown in Fig. 10a. $\delta_{\max , i} / h_{i}$ informs about the "apparent damage" and does not take into account the accumulated damage through plastic strain reversals. Cumulative damage is especially important in existing buildings designed according to earlier codes, since most of them have not been detailed for sustained resistance through many cycles of response in the inelastic range (Fajfar and Gaspersic 1996). The energy dissipated through plastic strains in the structural elements of each story, $E_{h i}$, is an indicator of the damage at 
the story level (Akiyama 1985). In the prototypes without infill walls (models P1 and P2), $E_{h i}$ can be obtained by integrating the story shear force $Q_{i}$ versus inter-story displacement $\delta_{i}$. In the prototypes with infill walls, $E_{h i}$ is the sum of the energy dissipated by the frame $E_{h, \text { frame,i }}$ and the energy dissipated by the walls, $E_{h, i, \text { wall }}$, and both components can be calculated in a similar way, by splitting $Q_{i}$ into the shear sustained by the frame, $Q_{i, \text { frame }}$, and that sustained by the wall $Q_{i, \text { wall }} . E_{h i}, E_{h i, \text { frame }}$ and $E_{h i, \text { wall }}$ can be normalized by the product of the corresponding yielding forces, $Q_{y i}, Q_{y i, \text { frame }}, Q_{y i}$, wall respectively, and lateral displacements, $\delta_{y i}, \delta_{y i, f r a m e}, \delta_{y i}$, wall at yielding by means of cumulative plastic strain ratios defined by:

$$
\eta_{i}=\frac{E_{h i}}{Q_{y i} \delta_{y i}} ; \quad \eta_{i, \text { frame }}=\frac{E_{h i, \text { frame }}}{Q_{y i, \text { frame }} \delta_{y i, \text { frame }}} ; \quad \eta_{i, \text { wall }}=\frac{E_{h i, \text { wall }}}{Q_{y i, \text { wall }} \delta_{y i, \text { wall }}}
$$

A preferable seismic design should aim to attain a uniform distribution of $\eta_{i}$ among the stories. When the value of $\eta_{i}$ is the same in all stories, the plastic strain energy is considered to have been dissipated in an optimal way (Akiyama 1985), and damage concentration does not take place. Figure $10 \mathrm{~b}, \mathrm{c}$ and $\mathrm{d}$ show the distribution of $\eta_{i}, \eta_{i, \text { frame }}$ and $\eta_{i, \text { wall }}$ for the prototypes investigated. It can be seen that while $\eta_{i}$ is nearly constant among the stories in prototype $\mathrm{P} 1, \eta_{i}$ is twice as large in the first story than in the rest of the stories of prototype $\mathrm{P} 2$. This damage concentration in the first story is exacerbated in the prototypes with infill walls (models P1-W and P2-W): in the first story the infill walls collapsed and the plastic hinges at both ends of the columns approached their ultimate capacity.

Another well known index of damage for RC structures is the one proposed by Park and Ang (1985), $I_{P_{A}}$, which takes into account both the damage associated with the maximum deformation and the cumulative damage. $I_{P A}$ ranges from $I_{P A}=0$ (no damage) to $I_{P A}=1$ (failure). $I_{P A}$ was calculated for each story and split in two parts: the damage on the beams and the damage on the columns, as shown in Fig. 11. At the story level, Fig. 11 reveals that the damage in columns is clearly larger than in beams. Mcanwhile, Fig. 12 shows the damage state at the member end level for the central frame of the four prototypes. It can be seen that in the frames without infill walls (models P1 and P2), plastic hinges develop in several stories

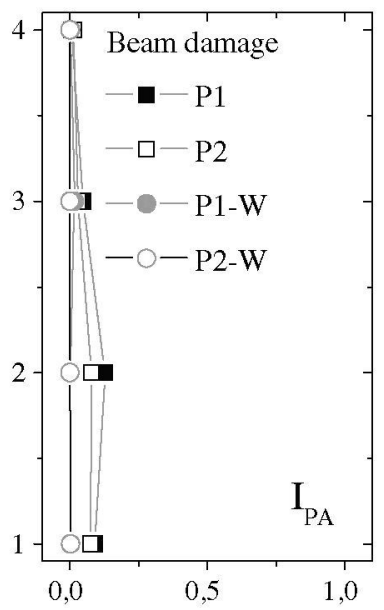

(a)

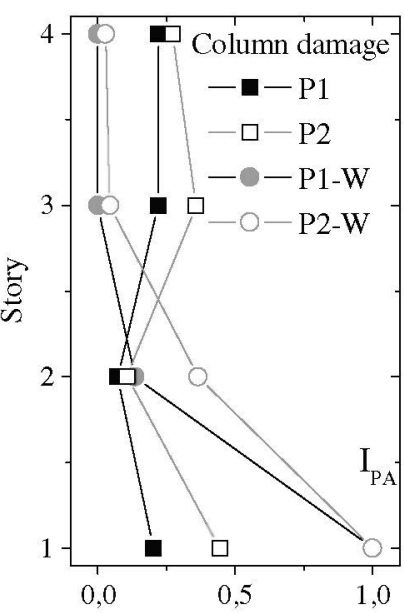

(b)

Fig. 11 Index of damage of Park and Ang $\left(I_{P A}\right)$ in: a In beams and $\mathbf{b}$ columns 
(a) Model P1

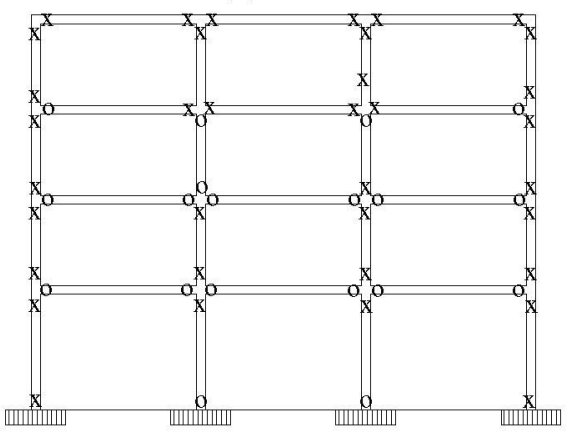

(c) Model P1-W

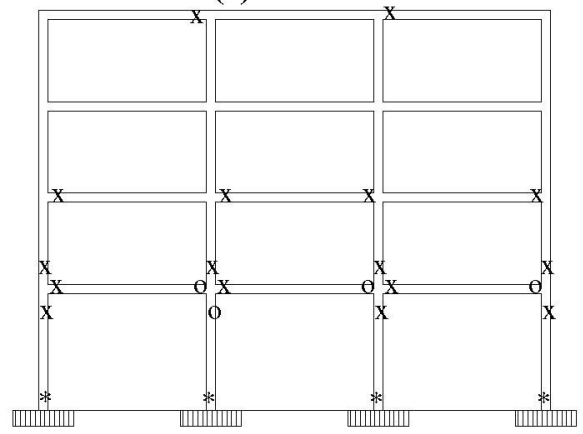

(b) Model P2

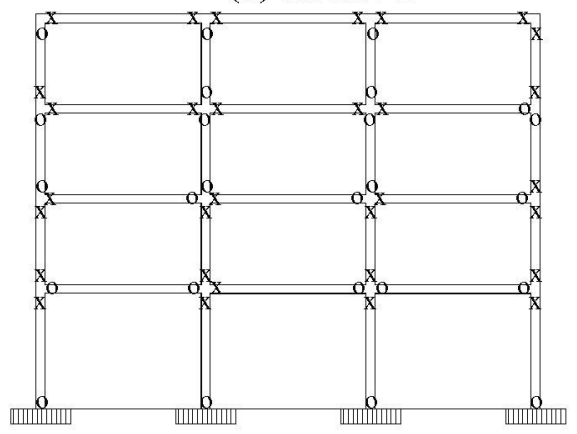

(d) Model P2-W

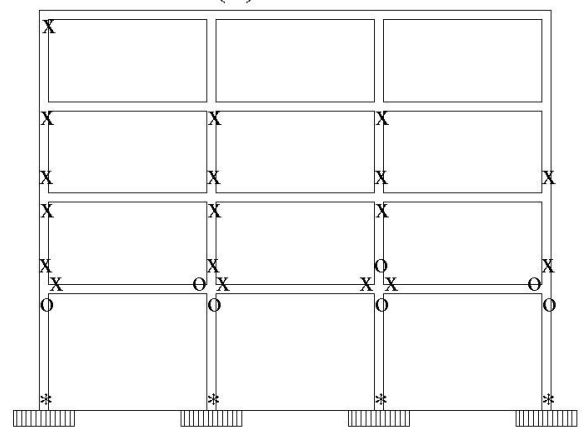

Fig. 12 Damage state at members ends in central frame prototypes: a P1; b P2; c P1-W; d P2-W. $x$ concrete cracking, o plastic hinge, * failure

but they do not reach failure. The number of plastic hinges at column ends is over three times greater in model $\mathrm{P} 2$ than in model $\mathrm{P} 1$. In contrast, in the prototypes with infill walls (P1-W and $\mathrm{P} 2-\mathrm{W}$ ), the severe concentration of damage caused the failure of the plastic hinges at the bottom end of all columns of the first story, while the columns and beams of the upper stories underwent just minor damage (cracking of concrete and inception of yielding of the reinforcing steel). This type of failure, commonly known as "soft story", was observed in many buildings with open ground story and weak claddings in Lorca, as illustrated in Fig. 2.

\subsection{Comparison between deformation and energy demands}

The relationship between displacement demand and energy demand constitutes a fundamental issue in the assessment of seismic vulnerability of existing building. Past research has identified correlations between top displacement $\delta_{\text {roof }}$ or maximum interstory drift $I D I_{\text {max }}$, and the input energy $E$ or the hysteretic energy $E_{h}$ in SDOF and MDOF systems (Fajfar 1992; Fajfar and Vidic 1994; Teran-Gilmore 1998; Decanini and Mollaioli 2001; Mollaioli and Bruno 2011). Focusing on MDOF systems, Mollaioli and Bruno (2011) defined the following parameters to characterize these relationships:

$$
\zeta^{\prime}=\frac{\sqrt{E / M}}{\omega_{1} \delta_{\text {roof }}} ; \quad \gamma^{\prime}=\frac{\sqrt{E_{h} / M}}{\omega_{1} \delta_{\text {roof }}} ; \quad \zeta^{\prime \prime}=\frac{\sqrt{E / M}}{\omega_{1} N h I D I_{\text {max }}} ; \quad \gamma^{\prime \prime}=\frac{\sqrt{E_{h} / M}}{\omega_{1} N h I D I_{\max }}
$$


Table 7 Energy and displacement demands

\begin{tabular}{lcccc}
\hline Model & $\zeta^{\prime}$ & $\gamma^{\prime}$ & $\zeta^{\prime \prime}$ & $\gamma^{\prime \prime}$ \\
\hline P1 & & & & \\
$\quad$ This study & 0.77 & 0.60 & 0.53 & 0.41 \\
$\quad$ Mollaioli et al & 0.84 & 0.61 & 0.45 & 0.32 \\
P2 & & & & \\
$\quad$ This study & 0.80 & 0.64 & 0.50 & 0.40 \\
$\quad$ Mollaioli et al & 0.85 & 0.62 & 0.44 & 0.32 \\
P1-W & & & & \\
$\quad$ This study & 0.83 & 0.47 & 0.26 & 0.14 \\
$\quad$ Mollaioli et al & 0.79 & 0.59 & 0.48 & 0.34 \\
P2-W & & & & \\
$\quad$ This study & 0.96 & 0.60 & 0.33 & 0.21 \\
$\quad$ Mollaioli et al & 0.79 & 0.59 & 0.48 & 0.34 \\
\hline$\quad$ & & & &
\end{tabular}

Here $\omega_{1}$ is the fundamental frequency, $I D I_{\max }=\max \left\{\left|\delta_{\max , i}\right| / h_{i}\right\}$, and $N \cdot h$ is taken as the total height of the building. For each model, Table 7 shows in the row "This study" the value of parameters $\zeta^{\prime}, \gamma^{\prime}, \zeta^{\prime \prime}, \gamma^{\prime \prime}$ obtained from the time history analyses explained in Sect. 8.2., with the second accelerogram (i.e. the one obtained merging the first and the second-mainshocks of the Lorca earthquake). For each model, Table 7 shows also in the row "Mollaioli et al" the $\zeta^{\prime}, \gamma^{\prime}, \zeta^{\prime \prime}, \gamma^{\prime \prime}$ obtained by Mollaioli and Bruno (2011) for moderately inelastic MDOF systems with $\mu=4$ in soil $\mathrm{B}$, subjected to near fault ground motions of magnitude $5.4 \leq M_{w} \leq 6.2$. It must be noted, however, that Mollaioli and Bruno (2011) obtained these results for well-designed frames able to develop a strong column-weak beam mechanism under strong ground motions. In the structures investigated in this study the formation of a strong column-weak beam mechanism was not ensured. Further, the ductility ratio $\mu$ was smaller than 4 (around 2). These differences mean that the results obtained by Mollaioli et al are not directly applicable to the structures of this study. As can be seen in Table 7, the values derived in this study are closer to those obtained by Mollaioli and Bruno (2011) in the case of the parameters that involve the top displacement (i.e. $\gamma^{\prime}$ and $\zeta^{\prime}$ ) and for the bare frames (i.e. models P1, P2), than in those that involve the maximum interstory drift (i.e. $\gamma^{\prime \prime}$ and $\zeta^{\prime \prime}$ ) and for the models with infill walls (i.e. models P1-W and P2-W).

\section{Discussion and conclusions}

The level of damage expected in RC frames with wide beams subjected to the recent Lorca earthquake (Spain) on May 11th, 2011, was investigated numerically using an energy-based seismic index method and nonlinear dynamic response analyses. The main goal was to clarify to what extent the damage observed in buildings in post-earthquake studies can be explained in view of the particular characteristics of this ground motion, which exceeded by far-three times - the design PGA prescribed by Spanish codes. Two four-story prototype buildings with masonry infill walls (models $\mathrm{P} 1-\mathrm{W}$ and $\mathrm{P} 2-\mathrm{W}$ ) were designed according to different Spanish codes in force in two periods of time: 1994-2002 and 2003-2008. Two counterpart prototypes without infill walls were also developed (models P1 and P2) to study their influence on the overall response of the building. To reproduce the worst scenario for the buildings, 
the direction of the ground motion in which the energy input by the earthquake reached maximum values was used. The following discussion and conclusions can be made:

1. The main shock of the Lorca earthquake exceeded by about four times the energy input implicit in the Spanish seismic code NCSE-02, and induced severe damage (level 4 or 5 in the EMS-98 scale) to a large number of buildings, most of them with structures consisting of RC frames with wide beams.

2. The results of pushover analyses show that the ductility at the story level is close to the elastic response reduction factor allowed by the Spanish code (2), but slightly below (up to $20 \%$ smaller).

3. The expected damage on the prototypes under the Lorca earthquake was assessed through an energy-based method that evaluates the expected damage in terms of an index $I_{v}$ that ranges from $I_{v}=0$ (no damage) to $I_{v}=1$ (collapse). It is found that in the prototypes with infill walls (models $\mathrm{P} 1-\mathrm{W}$ and $\mathrm{P} 2-\mathrm{W}$ ) $I_{v}$ clearly reaches the value 1 and therefore they are expected to collapse, as was actually observed. These results were corroborated by nonlinear dynamic response analyses. The reason for this behaviour is the extremely negative effect of the infill walls, causing more than $90 \%$ of the total energy input by the ground motion to contribute to damage concentrated on the first (ground) story. These results emphasize the importance of designs that address the interaction between nominally non-structural infill walls and the main frame. This problem can be approached essentially in two ways. One is to avoid the interaction by using special gaps between structural and non-structural elements at the critical sections of beams and columns, as recommended for example by Japanese codes (AIJ 1994). The other way is to provide the story where damage is expected to concentrate with sufficient energy dissipation capacity, for example by adding energy dissipators (Benavent-Climent 2011b).

4. The calculation of the index $I_{v}$ for the counterpart prototypes without infill walls (models P1 and P2) revealed that in the absence of the effect of the infill walls, the prototype building designed according to codes in force in the period 1994-2002 experienced less damage $\left(I_{v}=0.50\right)$ than the prototype designed in the period 2003-2008 $\left(I_{v}=1.0\right)$. These results were also confirmed by the nonlinear dynamic response analyses. The explanation for such findings is that the different concrete strengths used in designing prototypes P1 and P2 (17.5 and 25 MPa, respectively) led to different dimensions and nominal flexural strengths in the members; this made prototype $\mathrm{P} 2$ more prone to damage concentration than model P1. This fact can be seen in Fig. 10b: while in prototype P1 the normalized cumulative plastic strain energy $\eta_{i}$ is distributed evenly in all stories, in prototype $\mathrm{P} 2 \eta_{i}$ is twice as large in the first story as in the others. These results must not be interpreted in the sense that buildings designed according to codes from the period 1994-2002 are less vulnerable in general that those designed according to codes in force in the period 2003-2008. Rather, what these results emphasize is the paramount importance of controlling the damage distribution among the stories. In the case of conventional RC frames this can be accomplished by making the sum of nominal flexural strengths of columns larger than the sum of nominal flexural strengths of the beams framing into the joints (at least $20 \%$ larger, according to ACI-318-11). Another solution is to provide a lateral strength distribution close to the "optimum" one that makes $\eta_{i}$ approximately equal in all stories, as proposed by Akiyama (1985) or other authors. Since neither of these two conditions was satisfied in prototypes P1 and P2, reflecting common practice in the periods of time investigated, the damage distribution among stories remained uncontrolled, and for the particular models P1 and P2 investigated it meant worse conditions for model P2 than for model P1. It is worth emphasizing that the 
benefit of the prototype $\mathrm{P} 1$ compared to $\mathrm{P} 2$ is attributable to the different dimensions of the structural elements owing to the different concrete strengths used.

5. There are plenty of factors not taken into account in this study that could have influenced the response of the buildings, such as the quality of materials or the soil effects. Nonetheless, the authors believe that if damage distribution among stories had been controlled with an appropriate hierarchy of strength between beams and columns at the local plastic hinge level, or with an appropriate hierarchy of lateral strength among the stories at the story level, the damage caused by the Lorca earthquake in the RC frames with wide beams would have been much lesser. The results also emphasize that if the interaction between non-structural infill walls and the main frame had been avoided, some damage and cases of collapsed buildings could possibly have been prevented. This belief is sustained by the response of prototype $\mathrm{P} 1$ in this study, whose expected index of damage $I_{v}$ was found to be $I_{v}=0.5$, halfway between $I_{v}=0$ (no damage) and $I_{v}=1$ (collapse).

Acknowledgments This work received financial support from the Spanish Government under project BIA2011-26816 and from the European Union (FEDER). 